\title{
I. DE EERSTE ZANG VAN DEN NĀGARAKRËTĀGAMA.
}

DOOR

H. KERN.

Reeds meermalen is de aandacht gevestigd geworden op de neiging tot godsdienstig-wijsgeerig syncretisme waarvan Oudjavaansche geschriften, meer inzonderheid van Mahāyānistische dichters, blijk geven. In den Sutasoma, een romantische bewerking van een bekend Buddhistisch Jātaka, dat op zijne beurt niets anders is dan eeu voor didaktische doeleinden pasklaar gemaakte vervorming van den Kalmāșapāda-mythe, wordt de stelling verkondigd dat Buddha en Çiwa in wezen één zijn. Dit kunuen wij volkomen beamen, wanneer wij ons op nihilistisch standpunt plaatsen. Immers volgens een zekere Mahāyānistische theorie, zooals die o. a. in een inscriptie van Battambang voorkomt, is Buddha in wezen $\mathrm{kha}$, d. i. de ledige ruimte. Een ander woord voor $k \mathrm{ha}$ is $\bar{a} \mathrm{k} \overline{\mathrm{a}}$ ça, en tevens wordt het als synoniem beschouwd met ç ūnya, leeg, nul. Maar als verpersoonlijking van $\bar{a} \mathrm{k} \bar{a} c ̧ a$ wordt ook Çiwa beschouwd. Men verkrijgt dus deze vergelijkingen :

$\mathrm{Buddha}=\mathrm{kha}=\overline{\mathrm{a}} \mathrm{k} \overline{\mathrm{a}} \mathrm{c}_{\mathrm{a}}=\mathrm{ç}_{\overline{\mathrm{u}} \mathrm{n} y \mathrm{a}}$

en

Çiwa $=\bar{a} k \bar{a} c ̧ a=k h a=c \bar{u} n y a$.

Derhalve :

Buddha $=$ Ciwa $=$ O.

Men kan nog meer hieraan toevoegen. In Chāndogyopanișad 7, 12, 2 leest men: sa ya ākāẹam brahmety upāste, d.i. hij die den $\bar{a} \mathrm{k} \bar{a} c ̧ a$ (den onbegrensden ijlen aether) als het brahman vereert. Hieruit volgt dat er waren die het brahman (het hoogste beginsel) met $\bar{a} \mathrm{ka} c \mathrm{a}$ vereenzelvigden. Doch het $\mathrm{brahman}$ is naar mystieke opvatting ook $=\bar{a} \mathrm{tm}$ a n (algeest, 't hoogste levensbeginsel). In 't Bhāgavata-Purāṇa ${ }^{1}$ wordt de stelling uitgesproken, dat $\mathrm{kh}$ a het

1 Bh. P. 3, 5, 31 . 
kenmerk van den ātman is. Hieruit volgt nu deze reeks van gelijkstellingen :

Buddha $=$ Ciwa $=$ brahman $=$ ātman $=$ kha $=$ çūnya $=$ O. Zoo komen wij tot de lijfspreuk der Mādhyamika's, de fine fleur der Mahāyānisten: sarvam ç̄̄nyam, $\mathrm{Al}=\mathrm{Nul}$. Nihilistischer kan de verst vooruitstrevende philosoof het niet verlangen.

Het merkwaardige in den zang waarmede de Nāgarakrĕtāgama opent is niet alleen dit, dat de dichter, Prapañca, Çiwa-Buddha als een twee-eenheid beschouwt, maar dat met dit denkbeeldig wezen verder vereenzelvigd wordt datgene wat in elke secte, godsdienstige of wijsgeerige, als hoogste voorwerp van vereering beschouwd wordt. Als vertegenwoordiger van dat hoogste hier op aarde en in den tijd, geldt voor den hofdichter Zijne Majesteit de Koning Hayam Wuruk, anders genaamd Rājasanagara. Bij zulk een gezindheid vergeleken, is zelfs het verst gedreven Byzantinisme maar kinderspel. Of nu het volk in het algemeen die gezindheid deelde, mag betwijfeld worden. Ook buiten Java vindt men, gelijk bekend is, voorbeelden genoeg dat het hoofd van den Staat goddelijke vereering genoot; hetgeen niet wegnam dat menigmaal zoo'n soort god door lieden uit zijn volk of door zijn eigene liefhebbende verwanten als een hond uit den weg werd geruimd. Wat nu Java betreft, is er op grond van historische berichten reden om te twijfelen of de hofdichter in den vorm, waarin hij zijn slaafsche gevoelens kleedt, eene volksovertuiging uitspreekt, maar wel mag men aannemen dat de uiterlijke vormen van buitengewone onderdanigheid, waardoor de hedendaagsche Javanen zich nog van hun rasgenooten onderscheiden, overblijfselen zijn van hetgeen hun in de Middeleeuwen is ingeprent.

$\mathrm{Na}$ deze inleidende opmerkingen laat ik het woord aan den hofpoëet:

1. Om் nāthāya namostu te stuti nin atpada ri pada bhațāra nityaça | sañ sūkṣme tĕlěn in samādhi Çiwa-Buddha sira sakalaniṣkalātmaka | sañ Çrī-Parwwatanātha nātha nin anātha sira ta pati nin jagatpati | sañ hyan nin hyan inișty acintya nin acintya hana waya tĕmah niren jagat \|

2. byāpì byāpaka sarwwatatwagata nirguṇa ${ }^{1}$ sira rin apakṣa Waișnawa rị̣ Yogî̀çwara porușeñ Kapila Jambhala sakala sirān hyan in dhana | çrī-Wāgindra sirān hyan sakalaçāstra Manasija siren smarāgama | rỉ wighnotsāraṇaprayoga Yamarāja sira makawala-ñ jagaddhita \|

1 H.S. niguṇa tegen de maat. 
Deze twee strofen kan men aldus vertalen:

"Om! Hulde zij den Beschermer, U! lof van den steeds deemoedig zich buigende vóór de voeten van den Heer! Die uiterst fijn onzichtbaar (aanwezig) is in 't diepst van 't (ekstatisch) gepeins, hij, Ciwa-Buddha, (zoowel) met het stoffelijke verbonden, (als) onstoffelijk van aard; Crīparwwatanātha, de beschermer der hulpeloozen, hij, de heerscher over de wereldheerschers; de god der goden, die beschouwd wordt als de (of : het) ondenkbare der ondenkbaren (of : van 't ondenkbare, 't allerondenkbaarste), (doch tevens) - uiterlijk (d. i. waarneembaar) bestaande door zijne incarnatie in de wereld; aldoordringend, zich overal verbreidende, in al het zijnde anwezig, eigenschapsloos ' is hij voor de Wiṣnuieten; İçwara (God de Heer) voor de (theïstische) Yogins; Purușa (individueele ziel) voor Kapila (d. i. voor de aanhangers van de Sānkhyaphilosophie); Jambhala in concreten vorm is hij als de god des rijkdoms; Wāgindra (de Heer des Woords, Brahma) is hij als de god van alle wetenschappen; de Minnegod is hij in de leer der Minnekunst; in de middelen om hindernissen uit den weg te ruimen is hij Koning Yama, die het heil der wereld ten waarborg strekt."

De dichter heeft zijne metaphysische theorieën in zulk een waas van diepzinnige wijsheid gehuld, dat ze eenige toelichting behoeven, die ik zal trachten te verstrekken, voor zooverre ik 's mans bedoeling begrijp.

Het woordje om, waarmêe 't gedicht opent, klinkt bedenkelijk oubuddhistisch. Maar we weten nu eenmaal dat kras syncretisme een kenmerk is van 't Mahāyānisme, zooals dat op Java beleden werd. Eigenlijk is in 't algemeen 't Mahāyānisme besmet met onbuddhistische, vooral Ciwaietische bestanddeelen, zoodat de Voorindische Hīnayānisten in de $7^{\text {de }}$ eeuw tegenover Hiuen Thsang beweerden, dat het fel door hen bestreden Mahāyānisme een vermomd Ciwaïsme was. Aan die bewering, al is die te sterk uitgedrukt, ligt waarheid ten grondslag. Wat het wijsgeerig stelsel van den linkervleugel der Mahāyānisten, de Mādhyamika's betreft, dat is niets anders dan de tot de uiterste consequentie gedreven Wedānta, een volslagen Nihilisme. Of nu onze dichter ook de theorie:

1 Kan ook naar de formule van 't Sānkhya-stelsel opgevat worden als: nzoodanig dat de 3 guṇa's, hoedanigheden: sattwa, volkomen zuiverheid, rajas, hartstocht, ta mas, duisternis, nog niet als zoodanig tot verschijning zijn gekomen", derhalve nog niet ontwikkeld uit den toestand van chaos of 't niet. 
't $\mathrm{Al}=$ 't Niet" huldigt, blijkt niet. Hij maakt onderscheid tusschen sakala en nișkala - twee echt Çiwaietische termeu - en spreekt van de incarnatie van den of het ondenkbare; schijnt dus het bestaan van sakala, van de phaenomenale wereld, te erkennen. Maar dit bewijst niets, want voor dengene die 't Niet als 't eenig wezenlijke beschouwt, is dat wat zich aan ons als wereld en wat zich daarin vertoont, louter schiju, māya ; de wereld is niet, schijnt slechts te zijn. Dat klinkt zeer logisch en - zeer onzinnig. Doch onzinnig is het alleen voor hem die 't gezag der Rede erkent, en voor de verst gevorderde Mahāyānisten is de Rede sam mịti, verduistering, uit den booze, in tegenstelling tot de hoogere, ware wijsheid, paramārtha. Een dergelijke strooming kan men waarnemen in de gedachtenwereld van onzen tijd.

Met "de of het onzichtbaar aanwezige in 't diepst van gepeins" zal bedoeld zijn 't als monade, atoomachtig gedachte-beginsel van 't bewustzijn. Het geheele begrip is ontleend, al of niet rechtstreeks, aan een gewone voorstelling in de Upanișads, bijv. Chāndogyopaniṣad $3,14,3$ : eșa ma ātmāntarh ṛdaye a ṇi yān wrīher wā yawa $\bar{d} w \bar{a}$, deze ziel van mij, binnen in 't hart die kleiner is dan een rijstkorrel of een gerstekorrel".

In Çrīparwwatanātha kan çrī het gewone hoogheid aanduidende woord zijn, maar men zou de samenstelling ook kunnen oplossen in Crīparwata + nātha, d. i. de Beheerscher van Çrīparwwata. Noch de eene, noch de andere uitdrukking in haar geheel heb ik ooit in een Indisch geschrift ontmoet. Çrīparwwata als bergnaam komt dikwijls genoeg voor. Woorden synoniem met Parwwatanatha, heer der bergen, zijn ook niet zeldzaam, maar geen van alle past, behalve Girīça als benaming van Ciwa. $\mathrm{Nu}$ is deze reeds genoemd in de twee-eenheid C i iwaBuddha. Nochtans is het mogelijk dat hier op Ciwa gedoeld wordt in een bijzondere functie, want het is niets zeldzaams dat een mythisch wezen gesplitst wordt en dan verschillende namen ontvangt naar gelang van de functie die hem toegeschreven wordt. Zou soms onder de door den dichter gekozen uitdrukking de persoon van Bhațāra Guru schuilen, dien men noode mist bij een opsomming van hoogere wezens, waarvan de meeste alles behalve buddhistisch zijn? In de Pararaton wordt verhaald dat Bhațāra Guru aan de goden Ken Arok of Angrok, den stichter der dynastie waaruit de heerschers van Majapahit sproten, voorstelt als zijn zoon, en dat gezegde Ken Arok, volgens 't besluit der goden als koning den 
naam van Bhațāra Guru voeren zou. Niettemin heet Ken Arok een incarnatie van Bhațāra Wișṇu en ook een zoon van Brahma. Het is alsof Ken Arok, die in zijn jeugd een groote deugnitt was, na koning geworden te zijn, de goddelijkheid van Brahma, Wișṇu en Bhațāra Guru, al. Çiwa, in zijn heiligen persoon vereenigde. ${ }^{1}$ Hiermede vergelijke men Zang 40 van den Nāgarakrĕtăgama, waar men leest :

ṅūnī Çākābdhideçendu hana sira mahānātha ynddhaikawīra, |

sākṣāt dewātmakāyonija tanaya těkap Çrī-Girīndra prakāça |

D. i. Weleer in 't Çakajaar oceaan, hemelstreken, maan (d. i. 1104) was er een groot vorst, zeer heldhaftig in den oorlog, blijkbaar van goddelijke natuur, bekend als een niet uit een moederlijf geboren ${ }^{2}$ zoon van den Doorluchtigen Girīndra (Heer der bergen). Onbetwistbaar is hier met "Heer der bergen" Bhațāra Guru aangeduid. Ook verderop wordt Ranigah Rājasa, al. Ken Arok, genoemd Çrī-Girīndrātmaja en Çrī-Girīndrātmas̄un. Op grond van deze bewijsplaatsen, acht ik het boven geuite vermoeden dat de dichter met Çrī-Parwwatanātha Bhațāra Guru bedoelt, volkomen bevestigd. Terloops zij vermeld dat de goddelijkheid van den stichter der dynastie ook daarnit blijkt, dat hij na zijn dood "terugkeerde naar 't hemelrijk", mantuk in swarggaloka. ${ }^{3}$

$\mathrm{J} \mathrm{ambhala} \mathrm{heet} \mathrm{volgens} \mathrm{een} \mathrm{Indisch} \mathrm{Buddhistisch} \mathrm{Woordeuboek}$ ook Pūrwayakṣa, voorts Yakṣa, en Maṇibhadra. In 't "Kurzgefastes Sanskrit-Wörterbuch" wordt Maṇibhadra genoemd een Yakșa-vorst en broeder van Kubera. In ons Javaansch gedicht is met Jambhala klaarblijkelijk Kubera zelf bedoeld, de welbekende god des rijkdoms. Deze, ook Waiçrawaṇa geheeten, is een godheid die van ouds aan Buddhisten en Brahmanisten beide gemeen is. Dat Kubera ook bij de oude, rechtzinnige Buddhisten hooge vereering genoot, blijkt o. a. uit zijn beeld aan den Stūpa van Bharhut, waar zijn naam $\mathrm{Kupira} \mathrm{luidt.}$

Het zal nauwelijks noodig wezen op te merken, dat poruṣa als synoniem van ātman in "t Sānkhya-stelsel minder juist is voor puruṣa of pūruṣa. Poruṣa uit Skr. pauruṣa is "persoonlijkheid".

De Minnegod wordt beschouwd als de hoofdgodheid in de overgeleverde leer (āgama) der Minuekunst. Daaruit mag men opmaken

1 Pararaton, blz. 44, vg. Vgl. de Aanteekening van Brandes, blz. 53.

${ }^{2}$ De afkomst van Ken Arok, die hier Rañgah Rājasa heet, als ay onija, wijkt af van de voorstelling in Pararaton.

3 Nāgarak. Z. 40 , st. 5 .

$7^{\circ}$ Volgr. VII. 
dat er secten of genootschappen waren die om zoo te zeggen de religie der Min beleden. De dienst van Amor zal bij de Javanen niet minder in zwang geweest zịn dan die van Aphrodite-Venus en Astarte elders, en evenzeer een godsdienstig tintje gehad hebben. Maar men kan moeielijk een soort van vereering denken zó in strijd met alle beginselen van 't oude, echte Buddhisme als de dienst van Kāma. Aan 't hoofd van den Kāmaloka, de wereld der zinnelijke begeerten, staat volgens een gangbare voorstelling Māra, de Verleider, de Booze. Vandaar dat zelfs in het door den Buddhist Amara-Simha vervaardigde Woordenboek, Māra als naam van den Minuegod voorkomt. In brahmanistische geschriften is Māra als benaming van Smara, Kāma, zeer gewoon.

Het is mij niet recht duidelijk in welken zin Koning Yama werkzaam is bij 't uit den weg ruimeu van hindernissen. Dit is anders de specialiteit van Gaṇeça of Gaṇapati, die in 't geheel niet genoemd wordt, misschien omdat geen enkele secte hem als hoofdgod of souvereinen geest beschouwt. Gemakkelijker te verklaren is het dat Koning Yama in zijn hoedanigheid als Dharmarāja, Koning der Wet, het heil der wereld bevordert. Zonder de opperheerschappij der Wet kan de menschelijke maatschappij niet gedijen.

$\mathrm{Nu}$ volgen in den Eersten Zang nog drie strofen, welke aldus luiden .

3. nāhan don iñ umastutī pada nirāhyun umikĕta katen் nareçwara| san் Çrī-nātha ri Wilwatikta haji Rājasanagara wiçeșa bhūpati | sākṣāt janma Bhațāra Nātha sira n-an̉hilañakĕn i kalañka nin prajā| hĕnty an் bhūmi Jawātibhakti manukūla tumuluy i těken் digantara \|

4. rin Çākarttuçarena rakwa ri wijíl ṇ̣pati tĕlas inastwakĕn prabhu | an garbbheçwaranātha rin Kahuripan wihaga nira n-amānuṣādbhuta lị̣ḍun bhūmi kĕtug hudan hawu gĕrĕh kilat awilětan in nabhastala | guntur ttan் Himawān ri Kāmpud ananâ n்-kujana kuhaka māti tanpagap ॥

5. nāhan hīñan irān Bhațāra Girinātha sakala matĕmah prabhūttama |

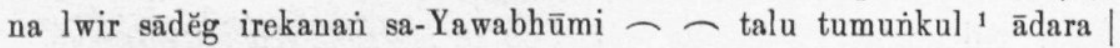
wipra kṣatriya waiçya çūdra caturāçrama sama nipuṇeñ samāhita | hĕnty ań durjjana maryy abuddhi kala kewala matakut i wīryya san் prabhu \||

D. i. "Zoo tracht ik Zijne voeten ${ }^{2}$ te loven, degene die de geschiedenis wil dichten van den Vorst, den doorluchtigen heerscher

1 De lezing van den tekst: cawatlukumunkul, is bedorven. Met caw a weet ik geen weg, tenzij bedoeld is wa ça in den zin van "onderworpen".

"Wij zouden zeggen: „allernederigst". Uit deze uitdrukking of synoniemen ervan heeft zich 't gebruik van 't Javaansche sampeyan ontwikkeld. 
te Wilwatikta (Majapahit), Koning Rājasanagara, den uitstekenden beheerscher des lands. Als een herboorte van Bhațāra Nātha maakt hij een einde aan de schandvlekken der onderdanen. Geheel en al is het land Java (hem) zeer onderdanig, genegen, en verder tot in andere streken.

"In 't Çâkajaar jaargetijden, pijlen, zon (d. i. 1256) werd de Vorst geboren, voorbestemd ${ }^{1}$ zijude tot heerscher. Toen onze koning en heer nog in den moederschoot was te Kahuripan, duidden miraculeuse voorteekens aan, dat hij een bovenmenschelijk wezen was: de aarde beefde, damp steeg op (van de vulkanen), er viel een aschregen, de donder rommelde, bliksemflitsen doorkliefden slingerend het luchtruim ; een donderend geraas maakte de hoofdberg ${ }^{2}$ Kāmpud; verdelgd werden de slechtaards en schelmen, machteloos omgekomen.

Dat was 't voldingend bewijs dat Bhațāra Girinātha (d. i. BhațāraGuru) zich in concreten vorm incarneerde in den soeverein.

Dus bleek het dat zoolang hij heerscht, geheel Java - onderworpen, zich eerbiedig voor hem buigt; de Brahmanen, Kșatriya's, Waiçya's, Çūdra's, de vier Āçrama's zijn alle evenzeer stipt in 't hun opgelegde ${ }^{3}$; de boosdoeners hebben opgehouden slecht gezind te wezen, daar zij alle bevreesd zijn voor de mannelijke kracht des heerschers."

In deze verzen heeft de verheerlijking van Zijne Koninklijke Majesteit het toppunt bereikt. In ondubbelzinnige bewoordingen bestempelt de dichter zijn patroon, Rājasanagara, al. Hayam Wuruk, als den god Bhațāra Nātha op aarde herboren. Dat Bhațāra Nātha identisch is met Bhațāra Girinātha blijkt uit vergelijking met de laatste strofe van den. Eersten Zang, en na hetgeen hierboven werd angehaald uit Zang 40 , kan er geen twijfel overblijven dat met Girinātha, synouiem van Girīça, bedoeld is Bhațāra Guru.

Onder de uitdrukking digantara, andere streken, heeft de dichter vermoedelijk verstaan de wingewesten van 't rijk van Majapahit buiten Java; dus wat wij noemen : de buitenbezittingen. In allen geval is het zeker dat het gezag van den Oppervorst van Java zich in de $14^{\text {de }}$ eeuw nagenoeg over dezelfde deelen van den

1 Eigenlijk: goedgekeurd: $\mathrm{Vgl}$. wat in Pararaton blz. 8, 23 gezegd wordt omtrent Ken Arok: yata inastwakĕn sira bhiṣeka Bhațāra Guru, en vgl. de vertaling van Brandes, blz. 44.

2 Dit is, denk ik, bedoeld met Himawān, daar van den Himālaya op Java geen sprake kan wezen.

3 De woorden nipuṇen̉ samāhita zouden ook kunnen beteekenen: nervaren in vroom gepeins", doch dit schijnt hier minder passend. 
Indischen Archipel uitstrekte als in den nieuweren tijd het Nederlandsch gezag. Men zou geneigd wezen het er voor te houden dat die overeenkomst in de verbreiding van 't rijk van Majapahit en van Nederlandsch-Indië bij de Javanen niet onopgemerkt is gebleven en aanleiding heeft gegeven tot het geloof, in een Javaansche Babad uitgesproken, dat de Hollanders de rechtmatige erfgenamen zijn van de heidensche vorsten van Majapahit.

Uit de Pararaton, aangevuld met gegevens uit den Nāgarakrĕtāgama, weet men dat Hayam Wuruk de zoon was van Prins Kṛtawardhana en Hare Koninklijke Hoogheid van Kahuripan, die na den dood van haar broeder, Koning Jayanagara, gedurende de minderjarigheid van haren zoon met zoo krachtige hand de teugels van 't bewind voerde onder den naam van Tribhuwanottungadewī Jayawiṣnuwardhanì, of zooals in Zang 2 van den Nāgarakrĕtāgama opgegeven wordt : Tribhuwana-wijayottungadewì. Haar residentie was Kahuripan, waar zij zich met haar gemaal bevond, toen zij zwanger werd van hem die later als Hayam Wuruk, opperheerscher van Java zou wordeu. Uit Zang 2 weten wij ook dat de Sanskrit-benaming van Kahuripan was: Jìwana, klaarblijkelijk een vertaling van den oorspronkelijken, Javaanschen naam.

Wihaga beteekent eigenlijk "vogel", maar het heeft evenals het Latijnsche a ugurium een ruimere beteekenis gekregen, en wel om dezelfde redenen. Ook in 't Sanskrit is çakuna, vogel, gebruikelijk in den zin van "voorteeken", inzonderheid "goed voorteeken". Hetzelfde geldt van 't Grieksche oìvós.

Uit de bewoordingen van 't laatste vers in strofe 4 schijnt men te mogen opmaken dat kort vór de geboorte van Hayam Wúruk, een hevige uitbarsting van een vuurspuwenden berg plaats had, waarbij tal van menschen jammerlijk omkwamen. Dat de slachtoffers toevallig alle slechtaards en schelmen waren, zal wel alleen door den dichter uitgedacht zijn om 't geval treffender, profetischer te maken. Immers hij, wiens geboorte op zoo indrukwekkende wijze aangekondigd werd, zou blijken als heerscher de macht te hebben om booswichten een heilzamen schrik in te boezemen.

Wat wij in de laatste strofe omtrent de op Java heerschende maatschappelijke orde vernemen, leert ous niets nieuws. Staat en maatschappij waren op Java in 't Hindoe-tijdperk door en door brahmanistisch. Let men alleen op de menigte van Buddhistische heiligdommen, welke sedert het laatst $\operatorname{der} 8^{\text {ste }}$ eeuw tot in de $14^{\text {de }}$ op Java zijn verrezen, dan zou men een oogeublik geneigd zijn 
den invloed van 't Buddhisme zeer hoog aan te slaan. Doch de Oudjavaansche letterkunde is zóó overwegend Brahmanistisch; de nog bij de hedendaagsche Javanen levendige belangstelling in de figuren van 't Mahābhārata en Rāmāyaṇa, waarvan de Lakons getuigenis afleggen, bewijst een zóó groote vertrouwdheid met de Indische helden-sage bij 't Javaansche volk in vroeger tijd, dat men moeilijk aan 't Buddhisme een grooten invloed op de maatschappij en volksdenkwijzen vau voorheen kan toeschrijven. Nog heden ten dage zien wij dat die op Bali weinig te beteekenen heeft. Het is evenwel niet te ontkennen dat in de vorstelijke families het Buddhisme veel begunstigers en aanhangers vond, en hierdoor is te verklaren dat zoo oneveuredig veel heiligdommen van Buddhistischen oorsprong 't eiland sierden. Zulke prachtgebouwen konden alleen door de grooten der aarde gesticht zijn; 't volk in 't algemeen had daartoe de middelen niet.

\section{KORTE GESCHIEDENIS VAN KONING RĀJASA IN DEN NĀGARAKRËTĀGAMA.}

Hiervoor op blz. 400, werden twee regels uit Zang 40 van Prapañca's lofdicht op Hayam Wuruk aangehaald, waar gesproken wordt van den stichter der dynastie waaruit na verloop van tijd de vorsten van Majapahit voortkwamen. Zoo uitvoerig als in de Pararaton de geschiedenis vau den beruchten Ken Arok verhaald wordt, zoo beknopt is die in den Nāgarakrĕtāgama; een lange uitweiding over 's mans lotgevallen zou in 't gedicht dau ook geheel misplaatst zijn, daar de dichter niet anders beoogt dan in hoofdtrekken de geschiedenis der voorzaten van zijn patroon in herinuering te brengen. Het behoeft ons dus niet te verwonderen, dat zelfs de naam Ken Arok niet bij Prapañca voorkomt. Wel vermeldt hij 't merkwaardige feit dat Rañgah Rājasa - de Pararaton heeft eenvoudig Rājasa de zoon is van Bhațāra Guru, zooals wij reeds gezien hebben.

$\mathrm{Bij}$ alle overeenstemming aangaande hoofdzaken, is er toch eenig verschil in de voorstelling tusschen het gedicht en 't geschiedwerk. Met verwijzing naar 't geheele $1^{\text {ste }}$ Hoofdstuk van de Pararaton en de belangrijke Aanteekeningen van Brandes daarop, wil ik beproeven een vertaling te leveren van Zang 40 in den Nāgarakrẹ̆tagama, met weglating der eerste twee regels van strofe 1 , waarvan de 
vertolking boven op blz. 400 te vinden is. ${ }^{1}$ De laatste twee $\mathrm{p} \overline{\mathrm{a}} \mathrm{da}$ 's van st. 1 luiden aldus :

kapwārĕs bhakti sakweh parajana sumiwì jöñ nirātwań tumuñkul | Çrì-Rañgah Rājasa kyāti ṅaran ira jaye ṅ-çatru çūrātidakṣa ॥

D. i. "Met gelijk ontzag en onderdanigheid dienden alle klassen ${ }^{2}$ van lieden zijne voeten, eerbiedig zich buigende. Als Z. Maj. Rañgah Rājasa was zijn naam vermaard, die zijne vijanden overwon, een held en zeer bekwanm".

Daarop volgt de $2^{\text {de }}$ strofe van dezen inhoud:

deçāgön wetan in parbbata Kawi pĕnuh in sarwwabhogātirāmya | kuww angěhnyān kamantryan manaaran i Kuṭarājenaděh wwan nikābāp yekì ṅgwan Çrì-Girî̀ndrātmaja n-umulahakĕn dharmma mañgöñ kaçūran | tuștā nin sādhu naștā nin ahita ya ginön sthitya nin rāt subhakti \|

D. i. "In een groot landschap ten Oosten van den Kawi, vol van allerlei zeer schoone voortbrengselen ${ }^{3}$ was een $\mathrm{kuwu}$ (hoofdkwartier, legerkamp, hoofdplaats), dienende tot Mantrie-verblijf, Kuțarāja geheeten, door een talrijke bevolking gedrukt. Hier was het, dat de zoon van Girindra 4 zijn (bestuurs)plichten uitoefende en zich op krijgsdeugd toelegde. Opdat de goeden tevreden zouden wezen en de slechtgezinden verdelgd, streefde hij den ordelijken toestand van de zeer onderdanige bevolking des lauds te verzekeren".

In deze strofe komt het een en ander voor, waarover 't verhaal in de Pararaton geen licht verspreidt. Van de stormachtige jeugd van den godenzoon wordt geheel gezwegen. Een toespeling op het verblijf van den held in de streek ten Oosten van den Kawi, vindt men ook in 't geschiedboek, p. 13, waar o. a. gezegd wordt: "Allen beoosten den Kawi hadden ontzag voor Ken Angrok, die er toen pas aan dacht koning ( $\mathrm{r}$ atu) te willen worden, wat de lieden van Tumapĕl (ook) verlangden". "5 Bevreemdend is het dat de k u w u Kuțarāja in de Pararaton in 't geheel niet genoemd wordt. Wel is er sprake van een akuwu, d. i. bezitter van een $\mathrm{kuwu}$,

1 Geringe onjuistheden in den gedrukten tekst, voornamelijk fouten tegen de kwantiteit, verbeter ik stilzwijgend.

${ }^{2}$ Ik meen para hier te moeten opvatten als 't Javaansche woord, niet als het Skr. para, want Skr. parajan a beteekent „vreemden".

3 De beteekenis van bhoga laat zóóveel speelruimte toe, dat moeielijk te zeggen valt wat de dichter eigenlijk bedoelt.

- Als synonieme uitdrukkıng komt ook nog voor: Giripatī warasuta in Zang 38, slotvers.

5 Gemakshalve geef ik de vertaling van Brandes. 
met name Tunggul Amětung, die door Ken Angrok vermoord en wiens weduwe, Ken Dĕḍes, door hem tot vrouw genomen werd. Uit de bewoordingen van 't gedicht is niets van dien aard op te maken. Wel blijkt er uit dat de held als regent te Kuțarāja oorlogzuchtige plannen had. Hieraan gevolg gevende, trok hij ten strijde tegen den vorst van Kaḍiri, hetgeen vermeld wordt in strofe 3 :

rì Cākābdhîkṛ̣tāçañkara sira tumĕke Çrì-narendren Kaḍintĕn | sañ wìrānindita Çrì-Kṛtajaya nipunene çāstra tatwopadeça |

çìghrālah gön bhayāmrih malajĕñ anusup pājaran pāręwa çūnya | sakweh nin bhṛtya mukyan parapajurit asin kāri rin rājya çîrṇna |

D. i. "In 't Çākajaar oceaan, dobbelsteeu met vier oogen, Çankara's (1144) trok hij op tegen den vorst van Kaḍiri, den onberispelijken held, den doorluchtigen Kṛtajaya, ervaren in de heilige boeken en de ware leer. Weldra overwonnen, in groot gevaar, trachtte deze te vluchten, en sloop in een afgelegen, verlaten kluizenarij. Al zijn voornaamste dienaren, de krijgslieden van alle rangen en al wie in 't rijk achtergebleven waren, vonden den dood".

De oorlog tegen Kaḍiri wordt in de Pararaton uitvoerig beschreven op blz. 13 vg., waar van den vorst, aldaar Dangḍang Gẹṇ̦is genoemd, een gansch andere, minder gunstige voorstelling gegeven wordt dan in 't gedicht, waar ook de naam verschilt, doch dit is van geen beteekenis, aangezien Kṛtajaya de bhișeka, de koningsnaam is. Ten opzichte van de nederlaag en vlucht des vorsten van Kadiri (Daha) stemmen onze beide bronnen in hoofdzaak overeen; dat de een de plaats waar de verslagene een goed heenkomen zocht een dewālaya, tempel; de ander een pājaran, kluizenarij noemt, makt geen verschil van eenig belang. Ten aanzien van 't jaartal heerscht tusschen 't geschiedwerk en 't gedicht volkomen overeenstemming.

De gevolgen der overwinning van den "zoon van Bhațāra Guru" worden beschreven in strofe 4 :

ryy ālah san Çrì-narendreñ Kaḍiri girigiṛin tan sabhūmì Jawārĕs | prāptānĕmbah paḍa wwat sahanahana wijil nin sadeçānpasewa | tungal tan Jañgala mwañ Kaḍiri samasamānekanāthātiçakta | ṅkān tĕmbe nin̉ ḍapur mwañ kuwu juru tumameñ sāmya mańde sukeñ rāt |

D. i. "Na de nederlaag van den Doorluchtigen vorst van Kadiri werd het geheele land Java vervuld van grooten schrik en angst: zij kwamen hun hulde betoonen en boden, terwijl zij hun eerbiedige 
opwachtingen maakten, allerlei opbrengsten van 't land aan. Janggala en Kaḍiri werden vereenigd onder één machtig heerscher. Toen vond de dipur en de wuku'juru voor 't eerst bij 't algemeen ingang tot geluk der bevolking" .

Janggala is nog heden ten dage de naam van een distrikt in de residentie Soerabaja. In de Pararaton komt de naam niet voor, wel Tumapĕl. Blijkbaar zijn Janggala en Tumapĕl twee namen van een en hetzelfde gebied van niet zeer grooten omvang. Zelfs na de inlijving van Kaḍiri was het rijk waarover Rājasa heerschte niet zeer groot, zoodat de voorstelling van den dichter, alsof 't gehe ele land Java voor den overwinnaar van Kaḍiri sidderde en hem huldigde, schromelijk overdreven is.

Dapur en kuw u juru heb ik voorzichtigheidshalve onvertaald gelaten. Een der beteekenissen van diapur is "keuken"; kuw u juru laat zich verklaren als "tijdelijk verblijf voor kraamvrouwen". ${ }^{1}$ Zou eerst in de $13^{\text {de }}$ eeuw het maken van kookplaatsen en kraamvertrekken buiten's huis meer algemeen geworden zijn? Het is volstrekt niet onmogelijk, maar vooralsnog bezitten wij daaromtrent elders geen berichten.

In de slotstrofe van Zang 40 lezen we 't volgende:

man̉kin wṛddhy āměwĕh tan் prabhawa wibhawa rin Çrì-Girìndrātmasūnu | enak tāndĕl nikañ Yāwadharaṇi sumiwì jöñ nirāñ chatra nin rāt| rì Çākāsyābdhirudra krama kalahan irān mantuk in swarggaloka | kyātiñ rāt san dhinarma ${ }^{2}$ dwaya ri Kagĕněñan Çaiwa-Boddheñ usāna ||

D. i. "Steeds nam de macht en heerlijkheid $\operatorname{van}^{3}$ den eigen zoon van Girìndra toe. Verzekerd was de rust van 't Javaansche land, dat de voeten vereerde van hem die de beschermer der wereld was. In 't Çākajaar negen, ${ }^{4}$ oceanen, Rudra's (1149) had zijn overlijden plaats en keerde hij terug naar den hemel. Hij, de zoo vermaarde in de wereld, werd te Kajĕnĕngan plechtig ter aarde besteld in twee tjañdi's als gewezen Çiwaiet en Buddhist."

De dichter zegt niets omtrent de wijze waarop Koning Rājasa aan zijn einde is gekomen. Uit de Pararaton weten wij dat hij vermoord is op aanstoken van zijn stiefzoon, die hem in de regeering opvolgde en den koningstitel Nūṣapati of Anūṣapati voerde.

1 Vgl. Sundaneesch juru, ngajuru, enz.

2 De tekst heeft dinārma.

3 Er zal niń voor rin moeten gelezen worden.

$4 \mathrm{Sya}$ is slechts een andere spelling voor siya; voor den voorslag $a \mathrm{vgl}$. men de opmerking in KBWbk. onder sija. 
Het stilzwijgen van den hofpoëet over die onstichtelijke geschiedenis laat zich gemakkelijk verklaren, zoodat er niet de minste reden bestaat om de betrouwbaarheid van 't geschiedboek in twijfel te trekken. In Zang 41 wordt Anūṣapati eenvoudig "Zoon" van zijn voorganger op den troon genoemd, vermoedelijk opzettelijk. Als hoveling zal de dichter begrepen hebben, dat, hij de chronique scandaleuse van den stichter der dynastie moest laten rusten en het doen voorkomen alsof de vorst van Janggala en Kaḍdri, de voorzaat van Hayam Wuruk op den troon, ook de stichter van 't stamhuis was.

Moeielijker te verklaren is het gebrek aan overeenstemming tusschen den Nāgarakrĕtāgama en de Pararaton ten opzichte van 't sterfjaar des konings. Volgens Prapañca overleed hij in 1149 Çāka (1227 A. D), terwijl het geschiedboek die gebeurtenis stelt in Çāka 1169 (1247 A. D.), dus twintig jaren later. Als begin der regeering van Nūṣapati geeft dezelfde bron Çāka 1170 en als datum van zijn dood 1171. Hij zou dus maar é́n jaar geregeerd hebben. Volgens het gedicht kwam hij aan de regeering in 1149 Çāka en stierf hij in 1170 . Het verschil van 1 jaar is niet noemenswaard, zoodat het niet de moeite waard is er bij stil te staan. Van meer belang is de tegenstrijdigheid in de opgaven van 't sterfjaar. Wat moeten wij daarvan denken?

Oppervlakkig beschouwd, schijnt de datum 1169 Çāka als sterfjaar vaн Koning Rājasa geloofwaardiger dan 1149 , en wel om de volgende reden. Van de regeering van Anūṣapati weet de dichter niets anders te vermelden dan dat hij zijn vader opvolgde, over geheel Java heerschte, stierf en dat zijn beeld, als Çiwa voorgesteld, prijkt in den graftempel te Kiḍal. Zijn geheele geschiedenis, zonder vermelding van een enkel feit, wordt afgehandeld in én strofe, Zang 41. Dat is toch al te weinig voor een koning die twintig jaar aan 't bewind zou geweest zijn. Volgens 't eene bericht zou Rājasa vijf jaren over Tumapĕl (Janggala) en Kaḍiri (Daha) geregeerd hebben; volgens 't andere vijf-en-twintig. Het eene is evengoed mogelijk als 't andere. Hoe oud nu was Rājasa, toen hij Kaḍiri veroverde? In de Pararaton wordt zijn geboortejaar niet opgegeven; in 't gedicht wordt niet bepaald gezegd dat. hij in 1104 Çāka ter wereld kwam; de uitdrukking is, dat er in dat jaar een heldhaftig groot vorst, zoon van den god Girìndra, al. Bhațāra Guru, was. Nemen wij eens aan, dat zijn geboortejaar bedoeld is, dan was hij veertig jaar toen hij Kadiri onderwierp; 
waarin niets onwaarschijnlijks ligt. Volgt men de lezing van de Pararaton, dan bereikte hij den ouderdom van 65 jaar; volstrekt niet onmogelijk.

Zoolang wij geen andere gegevens te onzen dienste hebben, zullen wij ons wel wachten op al te beslissenden toon het geschil te beslechten. Bij voortgezet onderzoek of bij toeval kunnen nog geschriften en inscripties ontdekt worden, waarin nuttige gegevens voor de geschiedenis van Java in het tijdperk der vorsten van Tumapĕl en Majapahit voorkomen. Voorloopig hebben wij nog genoeg te doen met de reeds nu toegankelijke bronnen niet ougebruikt te laten. 